\title{
A randomized-controlled, double-blind comparison of the postoperative analgesic efficacy of caudal bupivacaine and levobupivacaine in minor pediatric surgery
}

\author{
Ahmet Sen ${ }^{1}$, Mehmet Salih Colak ${ }^{2}$, Engin Erturk ${ }^{2}$, and Yakup Tomak ${ }^{1}$ \\ Department of Anesthesiology and Intensive Care, ${ }^{1}$ Recep Tayyip Erdogan University, Rize, ${ }^{2}$ Karadeniz Technical University, Trabzon, \\ Turkey
}

Background: We compared the postoperative analgesic efficacy of caudal levobupivacaine with bupivacaine in pediatric subumbilical surgery.

Methods: Sixty American Society of Anesthesiologists I-II patients scheduled for elective minor surgery (1.5-7 years old) were randomly divided into three groups to receive caudal injections of study drugs at $0.5 \mathrm{ml} / \mathrm{kg}$. All patients received 0.1 $\mathrm{mg} / \mathrm{kg}$ oral midazolam 30 min before surgery. Group B received $0.125 \%$ bupivacaine, group L received $0.125 \%$ levobupivacaine, and group LF received $0.125 \%$ levobupivacaine $+0.5 \mu \mathrm{g} / \mathrm{kg}$ fentanyl. Blood pressure, heart rate and sedation (using a four-scale sedation score) were monitored perioperatively. During the postoperative period, an anesthesiologist blinded to the study groups used the Children's and Infants' Postoperative Pain Scale to monitor patients' pain and degree of sedation. The time before the first rescue analgesic was recorded as well as any side effects over the next $24 \mathrm{~h}$.

Results: The four-scale sedation and postoperative pain scale scores in all groups were identical. Blood pressure and heart rate measured at 15 min postoperatively were lower, and time to first rescue analgesic was longer, in Group LF compared to the others.

Conclusions: Caudal $0.5 \mathrm{ml} / \mathrm{kg}$ of $0.125 \%$ bupivacaine and levobupivacaine are equally effective for postoperative analgesia after subumbilical surgeries in pediatric patients. Addition of fentanyl may lower the required amount of local anesthetics. (Korean J Anesthesiol 2014; 66: 457-461)

Key Words: Bupivacaine, Epidural analgesia, Fentanyl, Levobupivacaine, Minor surgical procedures, Pediatrics.

Received: February 25, 2013. Revised: 1st, April 24, 2013; 2nd, July 19, 2013; 3rd, July 25, 2013; 4th, September 26, 2013; 5th, November 28, 2013; 6th, December 4, 2013. Accepted: December 6, 2013.

Corresponding author: Ahmet Sen, M.D., Department of Anesthesiology and Intensive Care, Recep Tayyip Erdogan University, Eğitim ve Araştırma Hastanesi, İslampaşa Mahallesi, Şehitler Caddesi No 74, 53100, Rize, Turkey. Tel: 90-464-213049, Fax: 90-464-217036, E-mail: ahmetsenau@gmail.com

(c) This is an open-access article distributed under the terms of the Creative Commons Attribution Non-Commercial License (http:// creativecommons.org/licenses/by-nc/3.0/), which permits unrestricted non-commercial use, distribution, and reproduction in any medium, provided the original work is properly cited. 


\section{Introduction}

Postoperative pain in children may cause psychological disturbances [1], so children of all ages, even newborns, should receive sufficient preemptive analgesia [2]. This improves the child's recovery, and leads to better satisfaction of the family [3-5]. Caudal anesthesia reduces the systemic analgesic requirement and provides effective postoperative analgesia in lower abdominal surgery in children [6]. The main factors determining the quality and level of the blockage are the dose, volume and concentration of the drug. As several studies report, $1 \mathrm{ml} /$ $\mathrm{kg}$ of $0.2 \%$ bupivacaine provides sufficient analgesia; however, the delayed mobility caused may be distressing for the child and parents [7].

Levobupivacaine is known to provide equal analgesia with less motor block than bupivacaine [7]. We aimed to compare the effectiveness of $0.5 \mathrm{ml} / \mathrm{kg}$ of $0.125 \%$ levobupivacaine with equal volume and concentration of bupivacaine in a double-blinded and prospective setting in pediatric subumbilical surgery.

The groups were compared using time to first rescue analgesic and postoperative analgesic efficacy as the primary outcomes. Possible side effects of low volume and low concentrations of local anesthetics and opioids were also investigated as secondary outcomes.

\section{Materials and Methods}

After gaining the approval of the local Ethics Committee and obtaining informed, written consent from families, American Society of Anesthesiologists I-II patients aged 1.5-7 years scheduled for elective subumbilical surgery, were included in the study. Patients with a history of respiratory or circulatory disease, liver or kidney dysfunction, hypersensitivity to study drugs, those who received preoperative analgesia and those in whom caudal anesthesia was contraindicated were excluded from the study. The study was planned and performed according to the Declaration of Helsinki.

A total of 60 patients were randomly allocated into three groups $(n=20)$ using sealed envelopes during the preoperative visit. All patients received $0.1 \mathrm{mg} / \mathrm{kg}$ oral midazolam $30 \mathrm{~min}$ before surgery. Their sedation level was monitored using a fourscale sedation score. Blood pressure, heart rate, and peripheral oxygen saturation levels were also monitored. An independent anesthesist, not involved in any other part of the study, prepared the drugs and the labels. Study drugs were administered according to groups: group B received $0.125 \%$ bupivacaine, group L received $0.125 \%$ levobupivacaine, and group LF received $0.125 \%$ levobupivacaine $+0.5 \mu \mathrm{g} / \mathrm{kg}$ fentanyl. All drugs were diluted with isotonic saline to achieve a total volume of $0.5 \mathrm{ml} / \mathrm{kg}$ and were administered caudally.
A second anesthesiologist, blinded to the epidural drugs, induced patients with $5 \mathrm{mg} / \mathrm{kg}$ thiopental and neuromuscular blockade was reached with $0.5 \mathrm{mg} / \mathrm{kg}$ atracurium. After endotracheal intubation, anesthesia was maintained with $40 \%$ $\mathrm{O}_{2}, 60 \% \mathrm{~N}_{2} \mathrm{O}$ and $1.5-3 \%$ sevoflurane. No analgesic agent was used during induction or intubation. Patients were placed in the lateral decubitus position. Under sterile conditions, sacral hiatus was localized between the bilateral sacral corni and a caudal needle (Epican ${ }^{\circledR}$ Paed Caudal, 22 G, Braun, Melsungen, Germany) was placed over the sacrococcygeal membrane at $\sim 60$ degrees to the coronal plane. After loss of resistance, the needle was directed upwards at an angle of 20-30 degrees with the skin and advanced 3-4 mm. Study drugs were administered according to group allocations and patients were placed into a supine position for surgery. No additional analgesic agents were administered during surgery.

The blood pressure, heart rate, and peripheral oxygen saturation levels were recorded before and at 5, 10, 15 and 30 min after caudal blockage, at the end of the operation and 15 min later. Patients with an Aldrete score higher than eight were discharged from the postoperative anesthesia care unit. Time to first rescue analgesic, Children's and Infants' Postoperative Pain Scale (CHIPPS) scores [8], and side effects (nausea, vomiting, motor blockage, hypotension, bradycardia, urinary retention) were monitored and recorded at 2, 4 and 24 h postoperatively.

\section{Statistical analysis}

The sample size was based on previous investigations of the efficacy of different concentrations of levobupivacaine for caudal block in children [9]. We estimated a $25 \%$ increase in time to first rescue analgesic. Based on an alpha error of 0.05 and a power of $80 \%$, we calculated that approximately 20 patients in each group would suffice. Results were expressed as means \pm standard deviation (SD). Distribution of data was analyzed using the Kolmogorov-Smirnov test. Normally distributed data (age, body weight, blood pressure, heart rate) were analyzed with an analysis of variance test, and data not normally distributed (duration of surgeries, time to first rescue analgesic, CHIPPS scores) with a Friedman test. Within groups, normally distributed data were analyzed with a paired t-test and analysis of not normally distributed data was done with Mann Whitney $U$ and Wilcoxon tests. A value of $\mathrm{P}<0.05$ was taken to indicate statistical significance. For post hoc analysis, the $\mathrm{P}$ values were adjusted as 0.05/(number of comparisons). All statistical tests were carried out using SPSS 15.0 (SPSS Inc., Chicago, IL, USA).

\section{Results}

The demographic data were not significantly different among 
Table 1. Demographic Data of Patients who Received Caudal Bupivacaine (Group B), Levobupvacaine (Group L) and Levobupivacaine + Fentanyl (Group LF)

\begin{tabular}{lllc}
\hline & $\begin{array}{c}\text { Group B } \\
(\mathrm{n}=20)\end{array}$ & $\begin{array}{c}\text { Group L } \\
(\mathrm{n}=20)\end{array}$ & $\begin{array}{c}\text { Group LF } \\
(\mathrm{n}=20)\end{array}$ \\
\hline Age (months) & $47 \pm 19$ & $42 \pm 19$ & $41 \pm 22$ \\
Weight (kg) & $18 \pm 4$ & $17 \pm 4$ & $15 \pm 4$ \\
Operation duration (min) & $54 \pm 22$ & $45 \pm 23$ & $49 \pm 23$ \\
Operation type (n) & & & \\
$\quad$ Hypospadias & 4 & 6 & 8 \\
$\quad$ Undescended testes & 8 & 7 & 5 \\
$\quad$ Inguinal hernia & 5 & 7 & 5 \\
\hline
\end{tabular}

Data are expressed as numbers for operation type, means \pm SD for others.

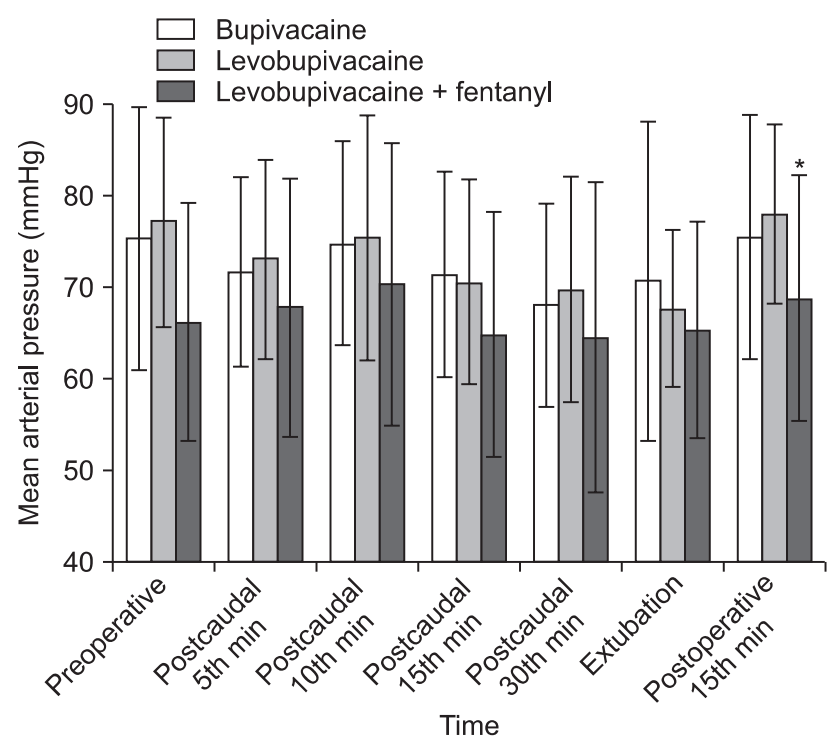

Fig. 1. Changes in mean arterial pressure during the perioperative period $(* \mathrm{P}<0.05$ compared with the other two groups).

the groups. Age, body weight and duration of operation are shown in Table 1.

Preoperative and intraoperative blood pressure were not significantly different among the groups. Blood pressure at $15 \mathrm{~min}$ postoperatively was significantly lower in Group LF compared to Groups B and L ( $\mathrm{P}=0.042, \mathrm{P}=0.015$, respectively) (Fig. 1).

The heart rate was significantly lower in Group LF at $10 \mathrm{~min}$ postcaudally compared to Group $\mathrm{L}(\mathrm{P}=0.014)$ and at $15 \mathrm{~min}$ postcaudally compared to Groups B and L ( $\mathrm{P}=0.040, \mathrm{P}=0.042$, respectively) (Fig. 2).

Time to first rescue analgesic was $246 \pm 163 \mathrm{~min}$ in Group B, $241 \pm 186 \mathrm{~min}$ in Group L and $358 \pm 172 \mathrm{~min}$ in Group LF. The time to first rescue analgesic was significantly longer in Group LF compared to Groups B and L (P $=0.040, \mathrm{P}=0.046$, respectively) (Fig. 3).

The CHIPPS scores showed a decreasing trend between $3 \pm 1$

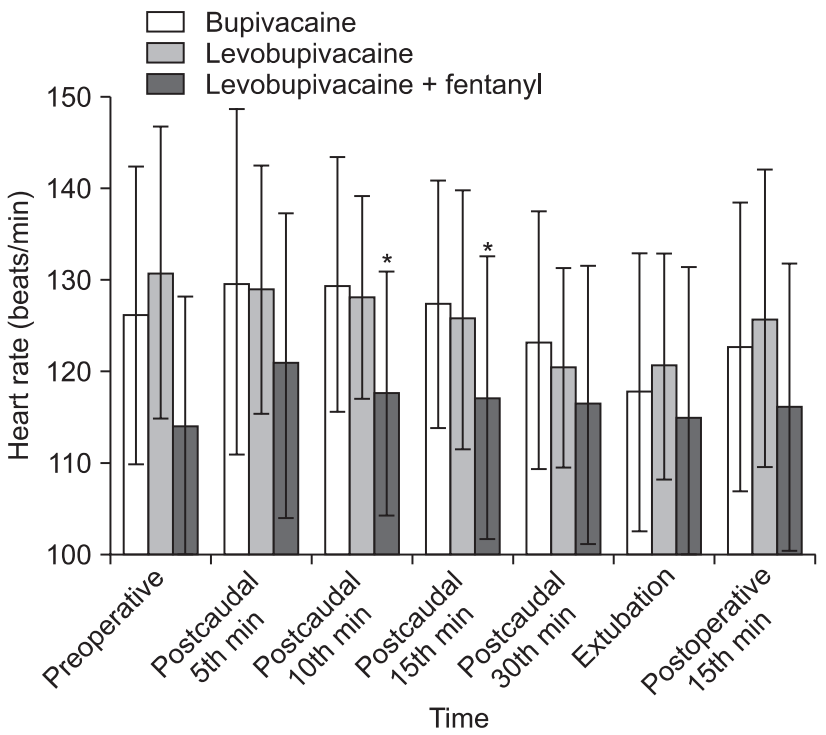

Fig. 2. Changes in heart rate during the perioperative period $(* \mathrm{P}<0.05$ compared with the other two groups).

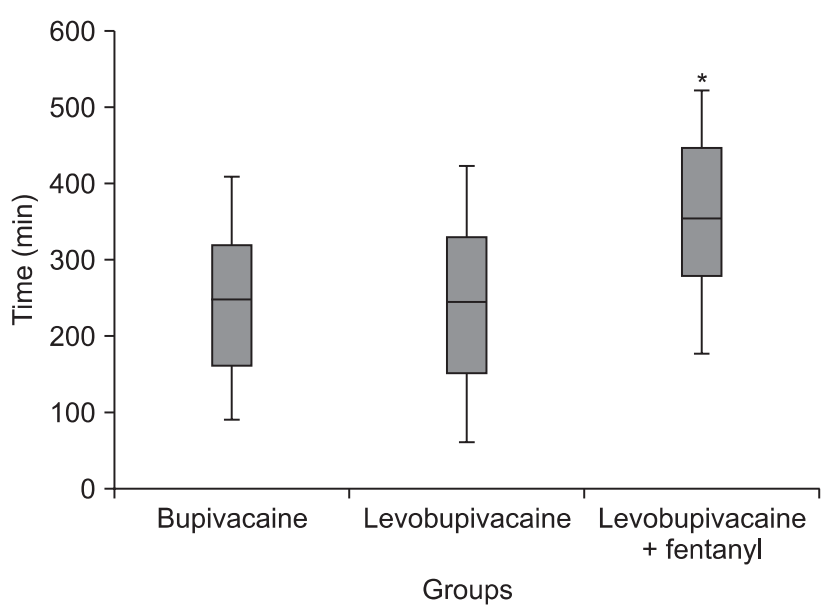

Fig. 3. Time to first rescue analgesic $(* \mathrm{P}<0.05$ compared with the other two groups).

at $15 \min , 2 \pm 1$ at $2 \mathrm{~h}, 1 \pm 1$ at $4 \mathrm{~h}$, and $0 \pm 0.5$ at $24 \mathrm{~h}$ postoperatively and showed no significant differences among the groups.

Emesis was observed in three patients in each group.

\section{Discussion}

This study showed that $0.5 \mathrm{ml} / \mathrm{kg}$ of caudal $0.125 \%$ levobupivacaine provides sufficient postoperative analgesia. Caudal blocks are routinely used in pediatric lower abdominal and genital surgery to provide postoperative analgesia, since it is easy to perform and provides reliable and efficient postoperative analgesia $[6,10,11]$.

Local anesthetic toxicity is the most serious intraoperative 
complication of neuroaxial anesthesia. Vertebral ossification is not complete until around age 6 years and in younger children, needles may penetrate the soft bones, resulting in interosseous injection of local anesthetics. Therefore selection of the local anesthetic with the least systemic toxicity risk and administration of the lowest dose required is important [12]. Myelination is not complete until about age 12 years, explaining the short duration of local anesthetics in small children. Cortinez et al. [13] report that following a caudal block with $2.5 \mathrm{mg} / \mathrm{kg}$ levobupivacaine in 1-month-old infants, levobupivacaine reached peak plasma concentration in $30 \mathrm{~min}$. They also report that although this frequently used dose is apparently safe, local anesthetic administration should be monitored in infants and small children, since local anesthetics have a longer half-life in these patients. They suggest that the prolonged half-life may account for sufficient analgesia seen at low concentrations of local anesthetics in small children. In contrast, some studies report a shorter half-life of local anesthetics in neonates and infants.

Bupivacaine is the local anesthetic used most frequently in pediatric patients. It is long-acting, has been in use for a long period, and its safety profile and side effects are well known [14]. Therefore, we used bupivacaine as the control drug. A newer local anesthetic, levobupivacaine, is reported to cause more vasoconstriction in lower concentrations $[15,16]$, thereby slowing systemic absorption, prolonging sensorial blockage and reducing the risk of toxicity $[17,18]$.

Caudal anesthesia with local anesthetics is prone to two main problems. High doses and concentrations to accomplish satisfactory analgesia cause prolonged motor block, delaying postoperative mobility and leading to side effects such as hemodynamic disturbances such as hypotension and bradycardia [9]. Preventing these side effects by administering a low concentration or volume of local anesthetics leads to insufficient anesthesia and analgesia. Ivani et al. [9] compared caudal blocks using $1 \mathrm{mg} /$ $\mathrm{kg} 0.125 \%, 0.2 \%$, and $0.25 \%$ levobupivacaine in children aged 1-7 years who were scheduled for subumbilical surgery. They reported that $0.125 \%$ levobupivacaine provides a short duration of analgesia but allows more rapid return to mobility, and $0.2 \%$ levobupoivacaine provides both sufficient analgesia and quick mobility. We found that $0.5 \mathrm{ml} / \mathrm{kg}$ of $0.125 \%$ local anesthetic was sufficient for most patients. This was apparent since the CHIPPS scores followed a decreasing postoperative trend and were similar between groups. However, we noticed that most of the patients who required a rescue analgesic earlier than $6 \mathrm{~h}$ were midpenile or scrotal hypospadias patients. We also noticed that addition of fentanyl postponed the requirement for rescue analgesics in these patients. We observed no intraoperative complications, but three patients in each group experienced emesis at home, likely due to residual general anesthesia and motion sickness.

In conclusion, caudal analgesia with $0.5 \mathrm{ml} / \mathrm{kg}$ of $0.125 \%$ bupivacaine and levobupivacaine is sufficiently effective for postoperative analgesia of subumbilical surgeries in pediatric patients.

\section{References}

1. Lee HM, Sanders GM. Caudal ropivacaine and ketamine for postoperative analgesia in children. Anaesthesia 2000; 55: 806-10.

2. Sümpelmann R, Münte S. Postoperative analgesia in infants and children. Curr Opin Anaesthesiol 2003; 16: 309-13.

3. Bhatt-Mehta V, Rosen DA. Management of acute pain in children. Clin Pharm 1991; 10: 667-85.

4. Berkowitz RA, McDonald TB. Post-operative pain management. Indian J Pediatr 1997; 64: 351-67.

5. Uguralp S, Mutus M, Koroglu A, Gurbuz N, Koltuksuz U, Demircan M. Regional anesthesia is a good alternative to general anesthesia in pediatric surgery: Experience in 1,554 children. J Pediatr Surg 2002; 37: 610-3.

6. Silvani P, Camporesi A, Agostino MR, Salvo I. Caudal anesthesia in pediatrics: an update. Minerva Anestesiol 2006; 72: 453-9.

7. Verghese ST, Hannallah RS. Acute pain management in children. J Pain Res 2010; 3: 105-23.

8. Büttner W, Finke W. Analysis of behavioural and physiological parameters for the assessment of postoperative analgesic demand in newborns, infants and young children: a comprehensive report on seven consecutive studies. Paediatr Anaesth 2000; 10: 303-18.

9. Ivani G, De Negri P, Lonnqvist PA, Eksborg S, Mossetti V, Grossetti R, et al. A comparison of three different concentrations of levobupivacaine for caudal block in children. Anesth Analg 2003; 97: 368-71.

10. Giaufré E, Dalens B, Gombert A. Epidemiology and morbidity of regional anesthesia in children: a one-year prospective survey of the French-Language Society of Pediatric Anesthesiologists. Anesth Analg 1996; 83: 904-12.

11. McGown RG. Caudal analgesia in children. Five hundred cases for procedures below the diaphragm. Anaesthesia 1982; $37: 806-18$.

12. Busoni P, Andreuccetti T. The spread of caudal analgesia in children: a mathematical model. Anaesth Intensive Care 1986; 14: 140-4.

13. Cortínez LI, Fuentes R, Solari S, Ostermann P, Vega M, Muñoz HR. Pharmacokinetics of levobupivacaine (2.5 mg/kg) after caudal administration in children younger than 3 years. Anesth Analg 2008; 107: 1182-4.

14. Da Conceicao MJ, Coelho L. Caudal anaesthesia with $0.375 \%$ ropivacaine or $0.375 \%$ bupivacaine in paediatric patients. Br J Anaesth 1998 ; 80: 507-8. 
15. Foster RH, Markham A. Levobupivacaine: a review of its pharmacology and use as a local anaesthetic. Drugs 2000; 59: 551-79.

16. McClellan KJ, Spencer CM. Levobupivacaine. Drugs 1998; 56: 355-62.

17. Huang YF, Pryor ME, Mather LE, Veering BT. Cardiovascular and central nervous system effects of intravenous levobupivacaine and bupivacaine in sheep. Anesth Analg 1998; 86: 797-804.

18. Van F, Rolan P, Brennan N, Gennery B. Differential effects of levo-and racemic bupivacaine on the EEG in volunteers. Regional Anesthesia and Pain Medicine 1998; 23: 48. 